\title{
Paisaje Urbano Histórico: aprendiendo de una ciudad paisaje, Segovia
}

\author{
Jimena Jordán-Salinas. Universidad de Valladolid, Valladolid, España. \\ Víctor Pérez-Eguíluz. Universidad de Valladolid, Valladolid, España. \\ Juan-Luis De las Rivas-Sanz. Universidad de Valladolid, Valladolid, España.
}

RESUMen | El concepto de Paisaje Urbano Histórico es una ambiciosa idea que hasta ahora adolece de cierta ambigüedad en su aplicación. Aprovechando casos como el de Segovia, íntimamente ligada al paisaje por su configuración y a la luz de la historia reciente de sus instrumentos de tutela del patrimonio, podemos aprender a interpretar el paisaje. Llegaremos así a aproximar una estrategia útil para gestionar y proteger los espacios urbanos históricos, y todo ello reivindicando la disciplina urbanística. El sistema propuesto reconoce tres dimensiones del paisaje, como son la geográfica, la morfológica y la escénica. Las tres han sido objeto de métodos consolidados de análisis en la historia del urbanismo, y en conjunto facilitarán un conocimiento integrado del paisaje urbano. Así, con conocimiento e inteligencia, este instrumento permitirá un modelo sostenible y flexible de gestión del patrimonio, alejado al mismo tiempo de arbitrariedades.

PALABRAS CLAVE | planificación urbana, urbanismo, patrimonio.

ABSTRACT | The concept of Historic Urban Landscape is an ambitious idea stressed by a certain ambiguity in its application. Taking advantage of cases such as Segovia, intimately linked to the landscape by its configuration and the recent history of its instruments of heritage protection, we can learn how to interpret the landscape. Thus, we will come to approach a useful strategy to manage and protect historic urban spaces, and all this will be done by claiming the goodness of urban discipline. The proposed system recognizes three dimensions of landscape: geographical, morphological and scenic. All three have consolidated methods of analysis in the history of urbanism, and together they will facilitate an integrated knowledge of the urban landscape. Thus, with knowledge and intelligence, this instrument will allow a sustainable and flexible model of heritage management, while avoiding arbitrariness.

KEYwORDs | urban planning, urbanism, heritage. 


\title{
El concepto de Paisaje Urbano Histórico: ¿̨recuperando el "buen urbanismo"?
}

\author{
The Historic Urban Landscape (HUL) concept includes the broader terri- \\ torial and landscape context and therefore goes far beyond historic centres \\ or ensembles. It both reflects and has helped to shape modern society and \\ consequently proves to be of great value for the understanding of our \\ current way of life.
}

(Forum UNESCO, 2009)

Este breve texto de la Organización de las Naciones Unidas para la Educación, la Ciencia y la Cultura (Unesco) sobre el concepto de Paisaje Urbano Histórico (PUH) pone de manifiesto tanto la ambición de una idea como la ambigüedad con la que esta se formula. En un contexto de constante evolución del significado y del alcance del concepto de patrimonio cultural, se propone el PUH como un "más allá" de los centros y conjuntos urbanos, los cuales, al parecer, han de ser reinterpretados. Sin abandonar la lógica patrimonial, se trata de ofrecer algo más, una nueva lectura capaz de incorporar ya sea su contexto geográfico, o bien un marco regional de referencia, algo que se expresa con la alusión a un contexto paisajístico y territorial más amplio. Dos razones para ello: por un lado, la escala ciudad y la dimensión centroconjunto son insuficientes; por otro, no se aspira únicamente a incorporar el medio físico al estudio, sino que al decir paisaje y territorio, se pretende un acercamiento a la sociedad moderna y una mejor comprensión de nuestra actual forma de vida. El paisaje parece significar, por lo tanto, la posibilidad de una visión más amplia del espacio antrópico al que centros y conjuntos históricos pertenecen, una mirada que valorice sus dimensiones naturales, culturales y sociales y no solo las patrimoniales. El nuevo concepto quiere relacionar los componentes materiales e inmateriales de lo urbano, con los usos y costumbres de los habitantes de cada lugar, donde, a lo largo de la historia, se han creado ciertos rasgos distintivos. El eco de los paisajes culturales es evidente, pero el problema ahora parece estar en cómo concretar ese "más allă” y añadir "algo más" al estudio de la morfología de dichos paisajes.

Es imposible obviar que la referencia al paisaje, al lado o no del interés histórico por la ciudad, conduce a un énfasis en la componente escénica de lo urbano y da un valor significativo a lo visual. Acudamos al Convenio Europeo del Paisaje (Consejo de Europa, 2000). La perspectiva paisajística no ofrece dudas, prioriza la percepción del espacio a su explicación, espacio/paisaje que comprende cualquier parte del territorio "tal como la percibe la población" (p. 2). Una percepción que será inútil si no conduce a una comprensión más profunda del propio paisaje. No en vano, el potencial simplificador de lo paisajístico se conjura (¿debería hacerlo?) acudiendo a la profundidad de la geografía, ciencia que hace del paisaje su objeto específico y que tiene capacidad para interpretar el contexto paisajístico y territorial en su complejidad, pero también a una antropología cultural capaz de comprender nuestra actual forma de vida.

Geografía y antropología impondrían la disciplina científica en el estudio del paisaje; sin embargo, la propuesta del PUH parece querer anclarse en una disciplina más abierta y relativa, el urbanismo. Ello se comprueba en la revisión del concepto 
de Paisaje Urbano Histórico que realizan dos importantes expertos de Unesco, Francesco Bandarin y Ron van Oers, impulsores de dicho concepto desde su origen. En El paisaje urbano histórico. La gestión del patrimonio en un siglo urbano (Bandarin \& Van Oers, 2012), se presenta el concepto de PuH como resultado de la evolución de las ideas que han orientado la conservación del patrimonio urbano, bajo la premisa de que lo que se está haciendo es insuficiente y se hace necesario reenfocar su protección en un contexto renovado de ordenación de las ciudades históricas. El gran objetivo es su gestión sostenible, la gestión del cambio en términos de preservación de los valores reconocidos, involucrando y dando respuesta a las necesidades de la sociedad, por oposición a un urbanismo defensivo basado en la negación selectiva del cambio. Sin embargo, el libro no avanza nuevas estrategias o desarrolla ideas innovadoras, ni siquiera en relación con la sostenibilidad, sino que se concibe como un manual que recorre figuras y ejemplos relevantes del urbanismo occidental reciente en relación con diversos aspectos de la intervención en las ciudades históricas. La aproximación paisajística a lo urbano histórico se apoyaría así en la relectura de urbanistas como Camillo Sitte, Kevin Lynch o Gordon Cullen que, entre otros, han ofrecido fórmulas y técnicas todavía útiles para comprender y gestionar la forma de lo urbano. En cierto modo, Bandarin y Van Oers, más que plantear algo nuevo en materia de planificación y gestión de las ciudades históricas, lo que proponen es una reivindicación del buen urbanismo. Así, se hace énfasis en una cultura, la específicamente urbanística, más rica de lo que se cree, muy distante de lo que Aldo Rossi (2015) ya denominó "funcionalismo ingenuo" (y destructivo, aunque dominante), y que tiene mucho que ofrecer, a pesar de que en tantos casos se haya banalizado o ignorado en su aplicación. En este sentido, el PUH trataría de fomentar una aproximación a lo urbano histórico fundada en lo mejor del conocimiento disponible sobre lo urbano y en lo que la disciplina urbanística puede aportar.

Con la publicación de Recomendación sobre Paisaje Urbano Histórico (Unesco, 2011), el concepto que tratamos se consolida y se impulsa para su aplicación práctica, a partir de su capacidad para reenfocar problemas y necesidades de las ciudades históricas. Tanto esta recomendación, como el resto de textos más o menos oficiales que impulsan el nuevo concepto, consolidan expectativas sobre su aplicación, aunque sin concretar una metodología y confiando su desarrollo a los instrumentos exigidos para las ciudades patrimonio mundial, esto es, los planes de gestión. Tampoco se esclarece en qué aspectos el "urbanismo convencional" es insuficiente. El concepto de Paisaje Urbano Histórico se impulsa al lado de una batería de ideas como las de enfoque integrado, sostenibilidad, participación y diseño urbano, a las que apenas se les da contenido.

Lo que queda claro es que la ciudad histórica a la que hace referencia el PUH no puede ser interpretada y gestionada como un distrito especial de la ciudad. Su consideración junto con la de la ciudad en su conjunto, y como parte relevante de la dinámica territorial, es imprescindible. Cualquier solución para los espacios urbanos históricos, desde el punto de vista tanto funcional como normativo, habrá de hacerse desde su integración en el conjunto del sistema urbano. Pero esto tampoco es algo nuevo. Los urbanistas pioneros en el reenfoque de la cuestión de los centros históricos, en particular los italianos como Giovannoni, Astengo o Campos 
Venuti, y en planes como los de Asís (1955-58) y Bolonia (1969-73), evitan hablar expresamente de centro storico, porque defienden una idea más amplia de città storica (Cervellati, Scannavini \& De Angelis, 1977).

La salvaguardia y puesta en valor de la herencia urbana histórica ha sido una constante del urbanismo contemporáneo, evolucionando desde la posguerra con la crítica a la destrucción funcionalista y con hitos concretos como la Ley Malraux, la Carta de Gubbio o el plan de Bolonia. Compatibilizar la conservación con una planificación más sostenible y centrada en necesidades sociales concretas ha sido y es una actitud permanente. Aunque aquí vamos a insistir en herramientas de análisis, estas han de servir a una planificación consecuente y a políticas de revitalización destinadas a resolver las tensiones entre la conservación y las necesidades sociales y funcionales actuales, en particular frente a los nuevos procesos que, como el turismo, se desencadenan con complejidad (Aparicio, Serrano \& León, 2018; Troitińo, 2009; Troitińo \& Troitińo, 2009). Las estrategias de regeneración urbana plantean para ello un singular punto de encuentro, que involucra cambios legislativos y acciones de planificación a todas las escalas.

Desde la lógica específica de la World Heritage List (wHL) de Unesco, en su obsesión por el Valor Universal Excepcional y sus atributos (identidad, universalidad, singularidad, etcétera), el análisis del paisaje visual 'en o de' la ciudad histórica prevalece por su fácil asociación con el 'carácter' de dichos conjuntos, eclipsando otras herramientas de análisis e intervención urbana muy eficaces. La visión interdisciplinar más compleja, imprescindible para detectar la estratificación de capas históricas y significados de la ciudad, corre el riesgo de apagarse en los paisajes directamente asociados con la identidad: el espíritu del lugar o genius loci. El contexto geográfico, su dimensión física, ambiental, los rasgos económicos y culturales de la sociedad local y de su trayectoria histórica, no son fácilmente aprehensibles. Por todo ello, la comprensión del paisaje necesita ir más allá de su percepción y acoger el conjunto de estudios que permiten desvelar sus rasgos y valores, tanto materiales como inmateriales. En definitiva, la utilidad y eficiencia del concepto de Paisaje Urbano Histórico depende de un complejo esfuerzo de conocimiento. Para ello hay que superar la controversia sobre la aplicación de un concepto polisémico y multidisciplinar como el de 'paisaje'.

La dificultad de la aplicación de tal concepto a la ciudad para enfocar problemas urbanísticos diversos no puede resolverse de manera universal. En cambio, en un contexto y con unos fines determinados, es posible una aproximación urbanística integradora y precisa. A ello aspira este artículo, con una propuesta sistémica y estructurada de lectura del paisaje urbano que pensamos útil para avanzar en la aplicación del PUH y contrastar algunas de sus potencialidades. Tratamos de combinar tres enfoques sobre el paisaje que disponen de recursos específicos y consolidados de análisis: el de la geografía, el de la morfología urbana y el específicamente visual o escénico. Al enunciado general de todo ello le asiste un caso concreto, Segovia, una ciudad que podemos considerar 'ciudad paisaje' y, en este sentido, campo ideal de pruebas para el pur. En Segovia lo paisajístico se detecta desde la primera aproximación física a la ciudad, en la que ya se intuye su estrecha relación con el territorio que la acoge. Los principales componentes de su patrimonio urbano 
(acueducto, alcázar, murallas, catedral, barrio) se manifiestan con rotundidad en un paisaje donde la obra del hombre y las condiciones naturales del lugar componen una urdimbre inseparable de relaciones. Así lo recoge la declaración de Segovia como Patrimonio Mundial de la Unesco (1985), al invocar varios criterios en su declaración sobre Valor Universal Excepcional, donde nos interesan sobre todo el (i) "Segovia representa en su conjunto una realización artística o estética única y una obra maestra del espíritu creador del hombre, en diferentes épocas y por diferentes razas y culturas que han contribuido a su creación. No solo se basa en sus monumentos tomados individualmente, como el Acueducto, la Catedral o el Alcázar, verdaderos hitos estructurantes de la villa, sino también por su configuración de la naturaleza urbanizada (valles de los ríos Eresma y Clamores), su ciudad amurallada, que constituye un paisaje de un valor remarcable que emana del espíritu creador y de la intervención del hombre" (Unesco, 2006, p. 1); y el (iv), que habla de un "conjunto arquitectónico y paisaje que ilustra una etapa significativa de la historia de la humanidad". Todo esto se comprueba en la percepción directa de habitantes y visitantes. La materialidad de dicho paisaje es tan elocuente que permite intuir lo intangible, un paisaje en el que se mezclan pasado y presente.

El pasado urbanístico reciente de Segovia demuestra cómo estos tres enfoques propuestos, presentes de forma diversa en los trabajos urbanísticos realizados, no siempre han dialogado entre sí. Por ello, la integración que aquí se plantea no es tanto conceptual como explicativa: los enfoques se articulan en la medida en que permiten construir una narración coherente sobre la forma urbana, su origen y condicionantes, su evolución histórica y su situación actual. El paisaje exige que la estructura narrativa no sea solo literaria sino comprensiva, resultado de un saber que articula conocimiento, análisis y valoración estética. Esta es la secuencia propuesta:

1. Territorio y ciudad: la aproximación geográfica contextualiza la ciudad en su región y perfila las relaciones con su entorno, describiendo las condiciones físicas y funcionales de un territorio concreto. Combinando saberes se explica el espíritu del lugar (genius loci), desde la forma del espacio natural a los demás elementos que configuran el paisaje y las lógicas de poblamiento y explotación del territorio. La dificultad técnica que implica la lectura de los mapas, en particular de los más especializados, contrasta con la panorámica, el paisaje desde la distancia o a vista de pájaro, que permite la visión de conjunto.

2. La forma urbana: el estudio de la morfología urbana permite explicar la estructura de la ciudad, su dinámica histórica y las características (físicas, funcionales y simbólicas) del espacio construido. Los planos de la ciudad son una herramienta básica que, con una interpretación precisa, nos acercan a los tiempos de la ciudad.

3. La escena urbana: la aproximación visual espontánea a lo urbano convive con la tradición pintoresca que caracteriza los lugares históricos. La imagen es clave para interpretar el espacio interior de la ciudad. Las disfunciones de identidad generadas por las imágenes habituales de un lugar se pueden corregir con el análisis del paisaje, complemento de la percepción de la gente y dirigido a las 
posibilidades de mejora. La percepción visual desvela el dinamismo del paisaje urbano y delimita el campo de proyecto.

La complementariedad de estos tres enfoques y el trabajo combinado pueden poner a prueba la aplicabilidad del PUH como herramienta de gestión de lo urbano histórico, estableciendo sus márgenes y sus condicionantes. Antes de cualquier intervención está el conocimiento. Para que al decir 'paisaje' se incorporen factores medioambientales y socioeconómicos, no solo culturales, hay que hacer un trabajo.

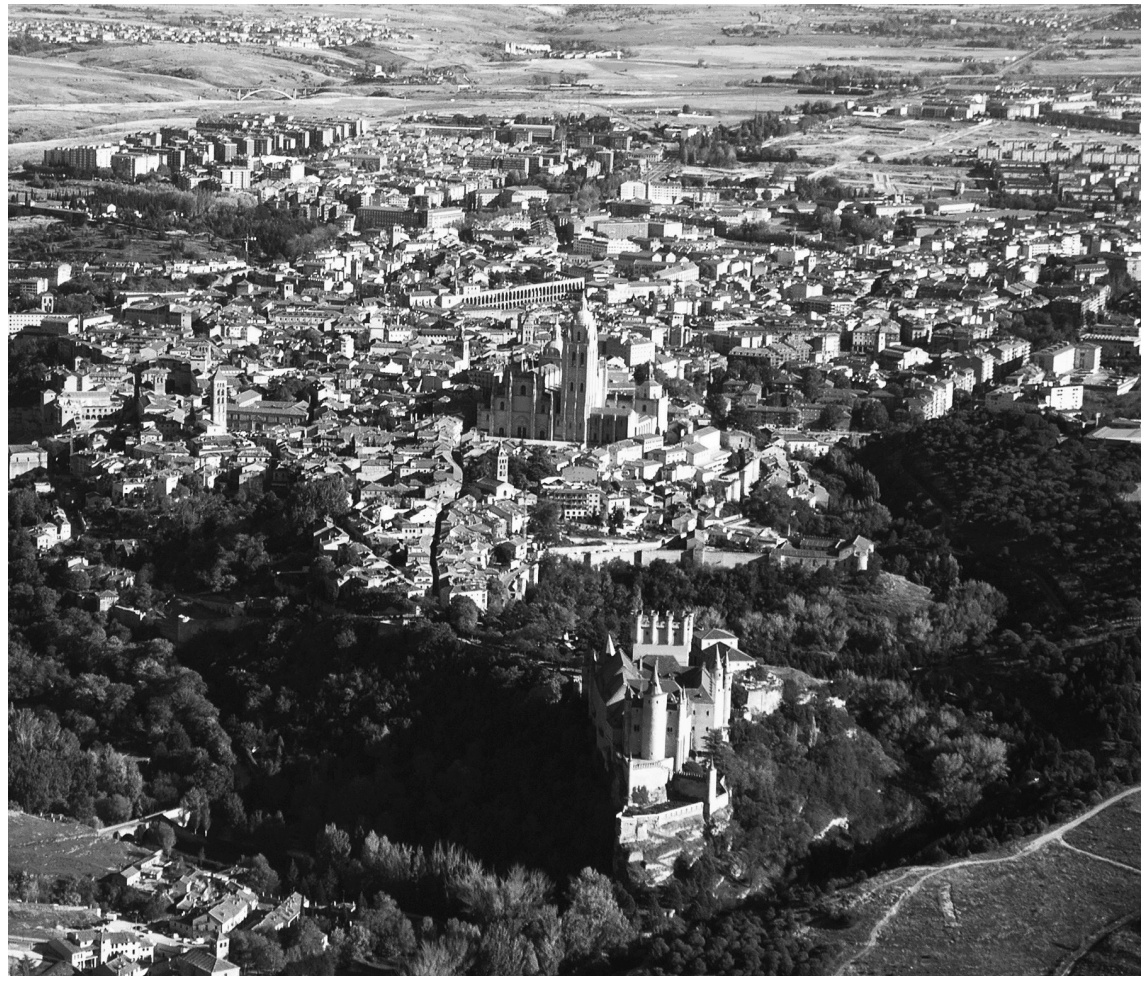

Figura I | Segovia desde el aire. Un emplazamiento único en el dorso de un espigón avanzado sobre el mar de Castilla con su castillo de proa, su bauprés central y su abierta galería de popa que contempla la estela de su navegación histórica (Chueca, 1998, p. 15).

FUENTE: FOTOGRAFÍA DE LOS AUTORES

La ciudad histórica es a la vez parte y enclave de la ciudad actual, un espacio en el que descansa su identidad. Como se comprueba en Segovia (figura 1), el espacio urbano histórico es un microcosmos inscrito en otro más amplio. Para un observador atento, el paisaje da acceso a la comprensión de las interacciones urbanas y permite establecer parámetros de diagnóstico. El paisaje, sus componentes, son el primer indicador de estado y calidad de lo que se desea proteger en cada caso. Comencemos viendo algunos contrastes. 


\section{La protección paisajística en Segovia: \\ de los Decretos de Vistas Protegidas de 1941 al paisaje en la planificación de la ciudad histórica}

El reconocimiento de los valores patrimoniales de Segovia se acompańa de una historia de hitos que, a lo largo de ochenta ańos, ponen de relieve los valores del paisaje. Diferentes reglamentos e instrumentos de planificación han dado forma a un marco normativo que permanece más o menos vigente en la ciudad. El primer Bien de Interés Cultural (BIC) declarado en Segovia fue su Acueducto y su cauce, el 11 de octubre de 1884, y hoy la ciudad cuenta con más de treinta monumentos BIC; el último, el Conjunto Histórico de la Plaza de Santa Eulalia, declarado en marzo de 2017. A nivel de patrimonio urbano, el conjunto de la ciudad antigua fue declarado monumento en 1941; en 1947 fueron declaradas y protegidas como Paraje Pintoresco las huertas y arboledas que circundan la ciudad amurallada, a lo largo del Eresma y el Clamores; y ya en 1985, Unesco incorporó a Segovia en la lista del Patrimonio Mundial.

Las coyunturas de cada instrumento y sus contenidos muestran una evolución cargada de contradicciones al proceder de normativas sectoriales dispares, donde permanece la voluntad de salvaguardar un paisaje histórico excepcional. El objetivo que caracteriza la protección ha sido siempre el control visual que reconoce la magnífica inserción de Segovia en su entorno natural y agrario. Se aspira a estabilizar una geografía local limitando todo aquello que se pueda considerar agresivo.

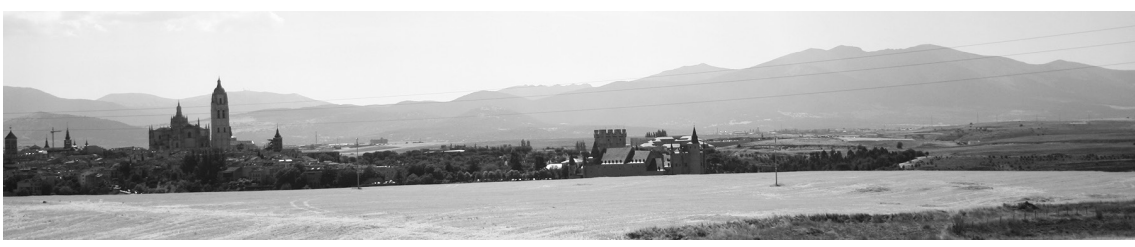

FIgUra 2 Perfil panorámico extramuros norte de Segovia. Fotografía tomada desde el núcleo urbano de Zamarramala, con la Sierra de la Mujer Muerta como telón de fondo y los campos de cultivo en primer plano, en una perspectiva que intuye, pero esconde, el valle del Eresma que antecede a la ciudad.

FUENTE: FOTOGRAFÍA DE LOS AUTORES

La secuencia de declaraciones de protección y planes especiales experimentada ha permitido la conservación no solo de los monumentos de la ciudad, sino de su morfología histórica y de los principales componentes de su paisaje. Pero lo singular en nuestro caso no es la tradicional protección de los monumentos o conjuntos y de sus entornos, sino el arraigo del paisaje mismo como objeto de protección.

Las primeras referencias al paisaje y entorno de la ciudad tuvieron lugar a la par que la protección del conjunto de la ciudad antigua (figura 2). Se formalizaron como decretos de protección de vistas aprobados oficialmente en 1941, con el objetivo de la protección visual de la ciudad histórica, en particular la vista desde sus 
alrededores, en prevención de la agresión que podría generar cualquier crecimiento urbano. En 1947, la figura de Parajes Pintorescos consolidó esta pionera lectura paisajística de Segovia. Los decretos respectivos se incorporaron a la declaración de Monumentos Histórico-Artísticos en los denominados Conjuntos Parciales, que se corresponden con las vistas panorámicas de San Justo y El Salvador y las vistas desde los miradores de la plaza del Alcázar y La Canaleja (figura 3). Junto con otros elementos singulares del paisaje cercano, estos ámbitos de protección, aunque no se definieron gráficamente en su día (generando interpretaciones dispares), forman un amplio espacio de protección de la ciudad histórica.

No es difícil comprobar que la lógica paisajística de protección se apoya en el relieve y en los principales elementos naturales (geomorfología y cursos de agua) que dan forma al enclave segoviano: los bien definidos valles de los ríos Eresma y Clamores y los parajes elevados de su entorno, como El Pinarillo y Las Lastras. En una distancia intermedia, los límites visuales están jalonados por los núcleos rurales periféricos, La Lastrilla, Zamarramala y El Sotillo, cuya evolución urbana sigue vinculando el carácter del paisaje en el entorno de la ciudad consolidada.

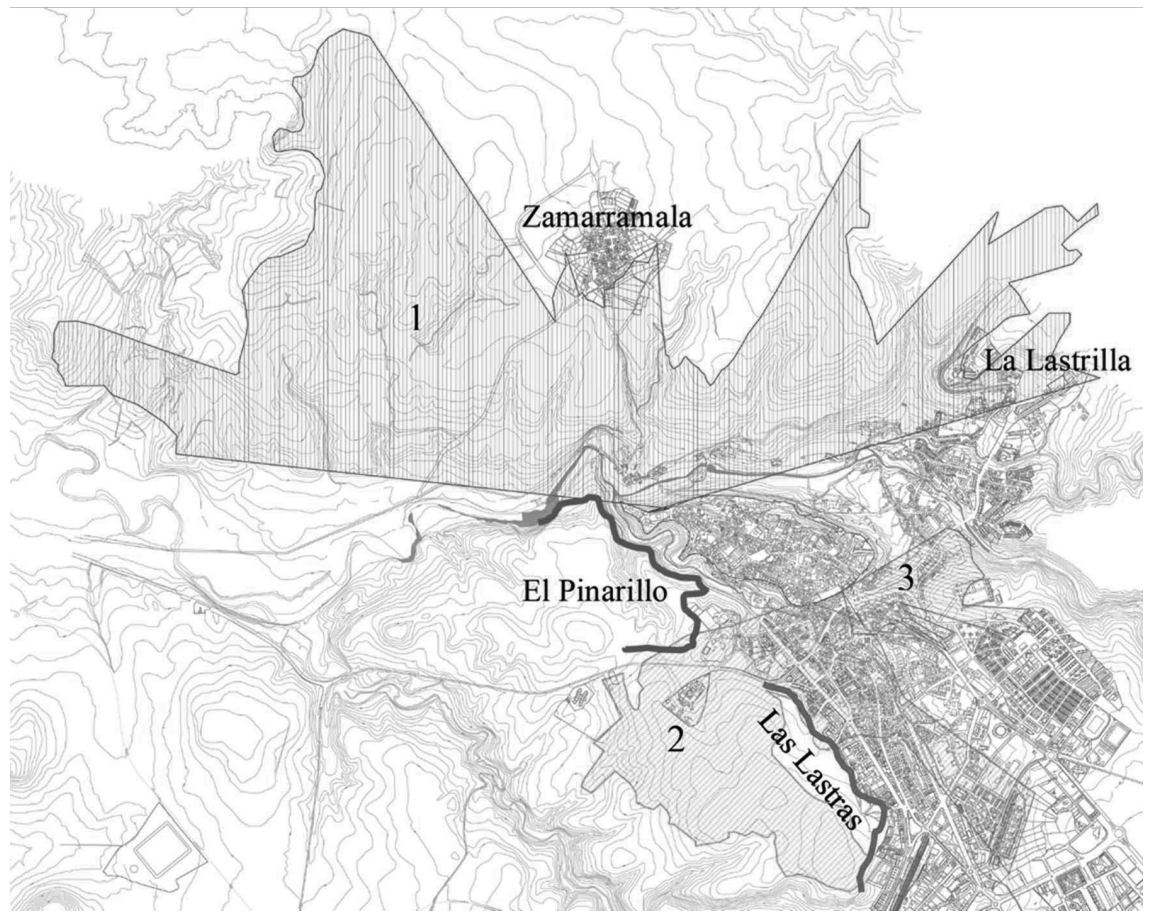

Figura 3 | Decreto de Vistas Protegidas en relación con la declaración de Conjuntos Parciales de la Ciudad (1941). (1) vistas desde el mirador del Alcázar, (2) vistas desde el mirador de la Canaleta y (3) vistas de San Justo y El Salvador.

FUENTE: ELABORACIÓN PROPIA 
La Declaración de Bien de Interés Cultural (Decreto de 12 de julio de 1941) constituye sin duda un primer acercamiento al paisaje urbano histórico de Segovia, pionero aunque limitado por la propia naturaleza de la protección visual. Sin embargo, es relativamente excepcional en un contexto en el que los entornos monumentales apenas son valorados, y enfatiza un sentimiento local, e institucional, de valoración del paisaje. Pero, sobre todo, supuso una forma concreta y útil de proteger la ciudad histórica, una intuición que ha sido de gran utilidad en la llegada del desarrollo urbano expansivo. Así, el crecimiento de Segovia se canaliza en el sur-este, con directriz hacia La Granja, sobre zonas cuya transformación afectan menos la imagen de la ciudad histórica.

En 1947 se aprobó un documento específicamente dirigido a la protección de algunos paisajes segovianos, con el sugerente enunciado de Parajes Pintorescos y centrado en espacios abiertos singulares, como el conjunto arbolado y la Alameda de Segovia, hoy incorporados al cinturón verde de la ciudad. Se trata de un esfuerzo pionero que anticipó diferentes lógicas de protección de los entornos urbanos y dio un valor específico al paisaje natural. Se reconocen así algunos jardines muy singulares de la ciudad, como la Alameda del Parral o el Paseo del Salón, o como las laderas de las murallas. Pero, además, se ha consolidado un reconocimiento excepcional de los corredores fluviales, incluidos los espacios de huertas, todavía reconocibles a lo largo del Eresma entre San Lorenzo y San Marcos. El Reglamento de Jardines y Alamedas (1948) consolidó una cultura paisajística que ha tenido continuidad en la ciudad y dado estabilidad a muchos de sus espacios más valiosos. La calidad actual del sistema de parques y jardines de Segovia da cuenta de ello (figura 4). Como ya se puede apreciar, esta nueva protección se superpone a los Decretos de Protección de Vistas, sin reconocer tal solapamiento ni resolver cómo se relacionan entre sí.

La creación de ámbitos de protección y la valoración de paisajes singulares va a permitir que lógicas proteccionistas posteriores puedan apoyarse en espacios concretos de la ciudad y su entorno. Efectivamente, su declaración como Ciudad Patrimonio de la Humanidad (1985), destaca en Segovia una realización artística en la que convergen el espíritu creador del hombre y la configuración de la naturaleza (Unesco, 2006, p. 1), resultado de un proceso de construcción a lo largo de diversas épocas y culturas. Sin embargo, la declaración no recoge en su ámbito el conjunto de los elementos que dan cuenta de dicha relación singular entre hombre y naturaleza, y no se formula en términos de paisaje. En fechas recientes, como exigencia de Unesco (2014), se ha definido en Segovia un área de amortiguamiento (buffer zone), reconociendo en parte los paisajes protegidos, aunque sin hacerlo explícitamente (figura 5). Esa delimitación se propone ad hoc como herramienta de gestión que proporciona una protección adicional al bien inscrito frente a problemas de origen externo. Se trata de un escudo de protección y de un elemento de conexión o transición al patrimonio, que define las características y los usos autorizados en dicha zona: un nuevo elemento de protección ańadido a los ya existentes y cuya coordinación ahora se demanda. 


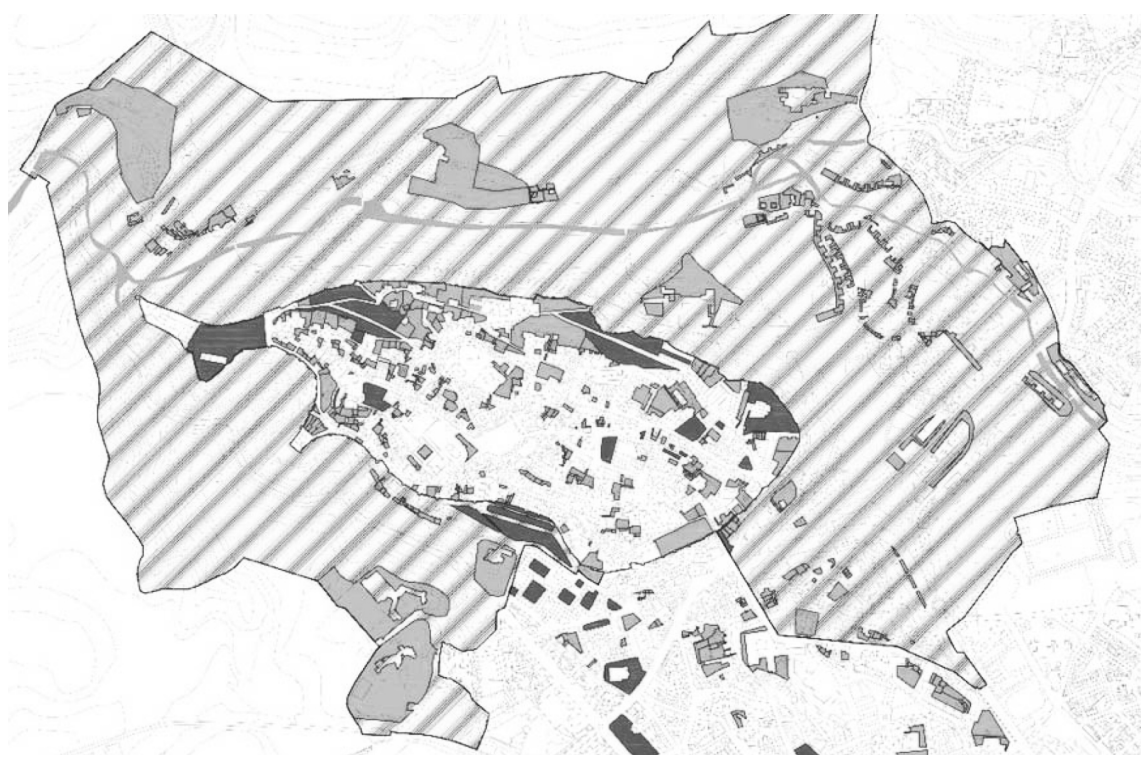

FIGURA 4 | El cinturón verde de Segovia y otras zonas naturales paisajísticas de la ciudad. Cinturón verde (zona rallada), jardines y parques públicos (gris oscuro) y espacios libres privados (gris claro), como espacios libres de protección ambiental de la ciudad histórica. El plano parte de la Declaración de Paraje Pintoresco del conjunto arbolado y alameda de la ciudad de Segovia (1947) y del Reglamento de Jardines y Alamedas de la Ciudad de Segovia (1948).

FUENTE: ELABORACIÓN PROPIA

Desde el punto de vista del paisaje, apenas se avanza. La protección de vistas que se inició con los Decretos de 1941 está formulada con más claridad (aunque, insistimos, no se dibujara), ya que el objetivo de ir más allá de la componente visual y panorámica no se concreta, y apenas se avanza en argumentos que dirijan la gestión y el uso sostenible de los espacios afectados.

De hecho, en Segovia, el área de amortiguamiento de la ciudad se superpone al resto de herramientas y plantea una sobreprotección difícil de administrar. No hay un trabajo de integración, como vemos, por lo que diferentes regulaciones protectoras inciden sobre el mismo espacio en cada caso, creando confusión y vulnerando los principios de eficacia y simplificación legislativa.

En España, son los planes especiales de protección (y a veces de reforma interior) los instrumentos habilitados por las legislaciones urbanística y patrimonial para los Centros Históricos, en una curiosa y no siempre eficaz convergencia. El problema es que dichos planes se circunscriben a los espacios incluidos dentro de sus ámbitos y su contenido paisajístico depende de la voluntad de sus redactores. En Segovia ello condujo a cierta arbitrariedad, como se evidencia en los Planes Especiales elaborados en los años noventa del pasado siglo, delimitados desde el planeamiento general sobre ámbitos parciales y con resultados dispares (De las Rivas, 2009a). El 
Plan Especial de Protección de las Áreas Históricas (PEAHIs, aprobado inicialmente en 2017), procura, sin embargo, dar coherencia al conjunto de espacios históricos de Segovia, agregando los ámbitos de los planes especiales que se fueron aprobando en las últimas tres décadas, armonizando y actualizando sus contenidos. Más allá de la regulación de los entornos de los BIC, la perspectiva paisajística surge en una aproximación al entorno mediante una zona de salvaguarda de las visuales y de la imagen de la ciudad, que incorpora la parte no monumental del acueducto, coincidiendo casi en su totalidad con la buffer zone (figura 6). No en vano, el bloqueo que sufre desde hace varios ańos la aprobación definitiva del PEAHIs se explica por el conflicto competencial planteado entre los criterios aplicados por los organismos habilitados en materia de urbanismo, patrimonio y patrimonio mundial.

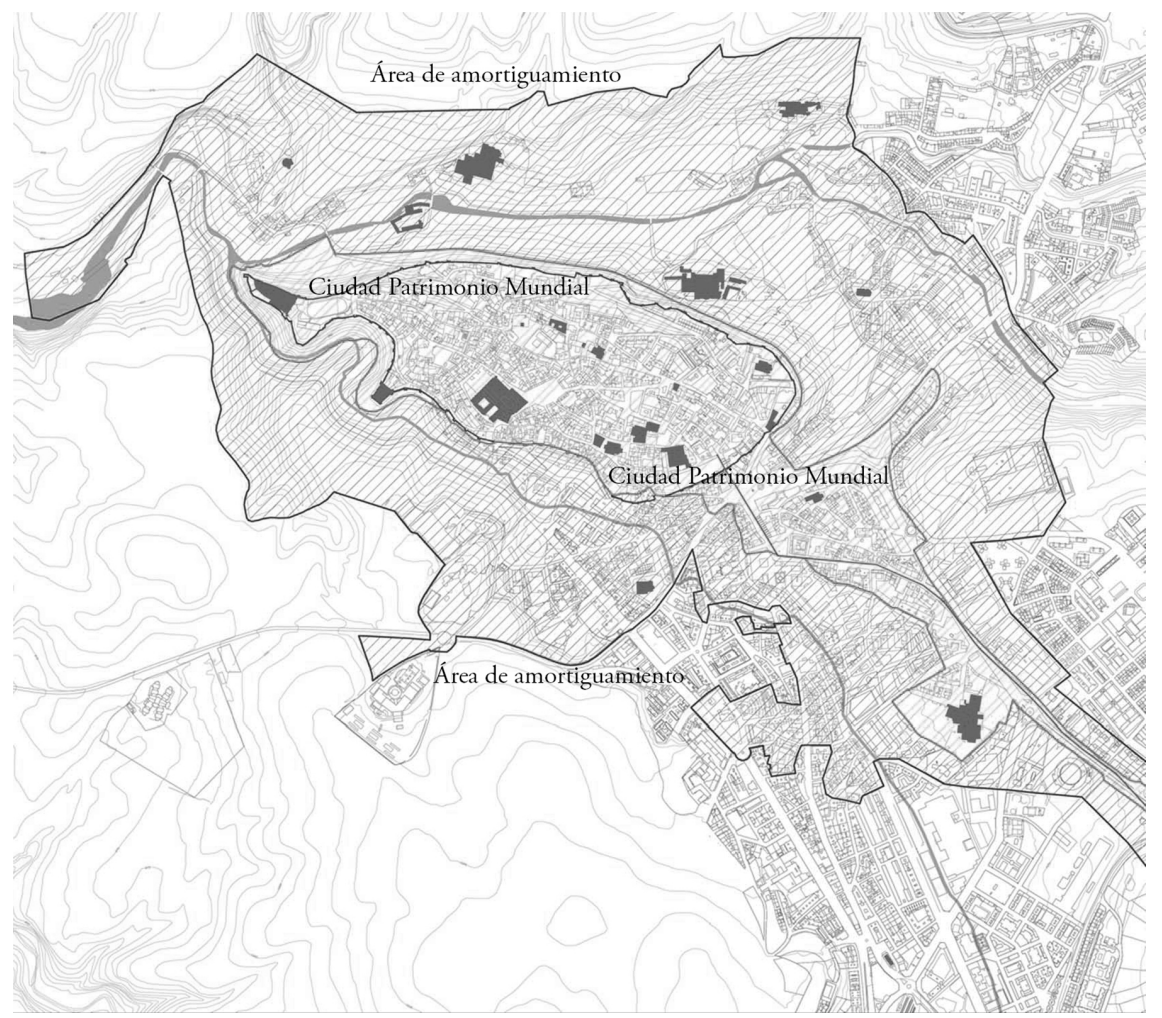

FIGURA 5 | Delimitación del área más cercana al recinto amurallado de la protección de Ciudad Patrimonio de la Humanidad por Unesco y de su Área de amortiguamiento. El ámbito de la Ciudad Patrimonio Mundial ocupa 134,28 hectáreas, mientras que el buffer zone casi cuadriplica su área. Como puede verse en el plano, hay casi el mismo número de elementos protegidos (gris oscuro) dentro del área de protección que en el área de amortiguamiento.

FUENTE: ELABORACIÓN PROPIA 


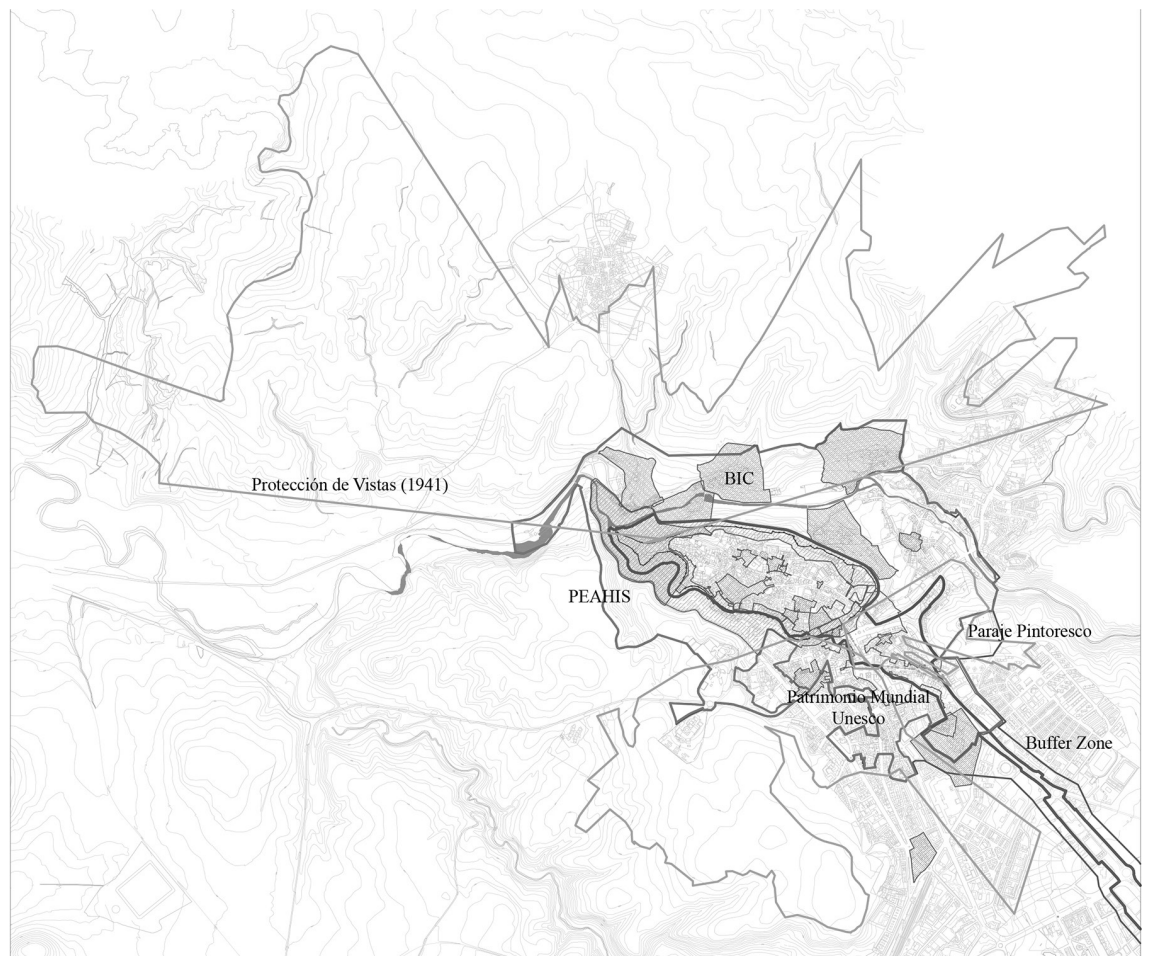

FIGURA 6 | Solape de las distintas delimitaciones proteccionistas que pueden encontrarse en la ciudad de Segovia. Decreto de Protección de Vistas (1941); cinturón verde y Monumento Histórico Artístico (1941); Entorno de protección de los BIC, Patrimonio Mundial Unesco (1985); Buffer Zone, (2014); PEAHIs (2017).

FUENTE: ELABORACIÓN PROPIA

Por último, Segovia está afectada por un instrumento de planificación territorial, las Directrices de Ordenación del Territorio de Ámbito Subregional de Segovia y Entorno (DOTSE, 2005), que establece un doble sistema de regulación paisajística supralocal en el área urbana, mediante unidades de paisaje que concretan criterios específicos de protección y gestión de los espacios abiertos, y la sistematización de los procesos naturales activos que catalizan los posibles riesgos naturales. Con la lógica propia de su escala, las directrices se desenvuelven en una cultura más próxima a la ecología del paisaje que a la protección patrimonial, pero con un contenido profundamente paisajístico útil para el desarrollo del PUH en su contexto territorial.

Los instrumentos que han tratado de proteger y revalorizar el paisaje de la ciudad de Segovia demuestran la dificultad de una perspectiva integrada, ya que cada uno responde a una coyuntura concreta y compete a disciplinas e instituciones diferentes. La superposición normativa es evidente, fruto de visiones y proyectos diversos. Sobresale el perfil proteccionista y apoyado en poco más que una delimitación dirigida a minorar impactos visuales. A pesar de ello, la evidencia es que en Segovia 
hay una rica cultura del paisaje que descansa en una tradición y empeño claros por conservar y poner en valor el paisaje de la ciudad, paisaje histórico y actual.

El concepto de Paisaje Urbano Histórico se enriquece de situaciones y casos como el de Segovia. Veamos desde perspectivas complementarias cómo interpretar el paisaje con el fin de fundar y desarrollar estrategias útiles para la protección y gestión de los espacios urbanos históricos, y lo vamos a hacer reivindicando la disciplina urbanística.

\section{Segovia en el paisaje: geografía de un enclave excepcional}

La aproximación más amplia y comprensiva al paisaje es la que realiza la geografía, fundada en el conocimiento científico del medio físico y del medio social y en herramientas de análisis capaces de describir cada faceta de los diferentes componentes del paisaje, ya que para no pocos geógrafos su disciplina entiende el "paisaje real" como su objeto de estudio (Ortega, 2000). Para comprender el genius loci de Segovia es imprescindible entender su lugar geográfico, en las estribaciones de la sierra de Guadarrama, sobre el promontorio que definen el río Clamores, en su desembocadura, y el Eresma. ${ }^{1}$ La ciudad se despliega en las vegas fértiles de sus ríos y se beneficia de los pequeños saltos de agua que facilitan las últimas formaciones graníticas del piedemonte, justo en el umbral de otro paisaje, el de la campiña cerealista. La economía de la ciudad, los batanes que definieron en la Edad Media su perfil productivo, participan tanto de la riqueza ganadera como del trigo de las cosechas. Revenga y Zamarramala, dos núcleos menores de Segovia, manifiestan ese contraste: un pueblo ganadero y un pueblo agrario sin abandonar los límites del municipio.

No pretendemos resumir las singularidades geográficas e históricas que dan forma al paisaje de Segovia, sino tan solo señalar la estrecha interdependencia entre lugar geográfico, economía local y evolución urbana. Es conocido el testimonio de un geógrafo pionero, el viajero del siglo XII Al-Idrisi, que señalaba que Segovia no era una ciudad, sino una "suma de aldeas", algo que va a caracterizar la estructura del asentamiento, su condición polinuclear ligada a la explotación de las vegas fértiles y a las estructuras ganaderas, y que va a determinar su morfología urbana.

Así, cuando se levanta la muralla medieval, quedan fuera arrabales y núcleos. En íntima relación con el relieve, la muralla se limita al perímetro del cerro. El amplio espacio que se abre bajo el Acueducto actúa de charnela, reafirmando la topografía de laderas y las vegas y favoreciendo un amplio lugar de acceso a la ciudad alta y encuentro. Se trata de una relación que va más allá del uso histórico del Acueducto, ingenio y río interior, haciendo en Segovia casi una costumbre la imbricación de arquitectura y paisaje, desde el Acueducto al Alcázar, jalonado por los torreones de casas fuertes e iglesias. El espacio alto intramuros no solo cumple una función defensiva. Es también el espacio levítico y señorial, una ciudad alta que se contrapone a los arrabales extramuros, de condición popular, al lado de un singular conjunto de monasterios que se enclavan alrededor de la ciudad, un amplio puzle donde lo construido se mezcla con espacios de cultivo.

El geógrafo segoviano Eduardo Martínez de Pisón (1976, 1977) realiza muy pronto lecturas complementarias del paisaje urbano de Segovia y de su territorio. 
La naturaleza, comenzando por su sustrato geológico, es el primer condicionante en la historia de Segovia y la principal razón de ser de su origen estratégico, de su lógica defendible y de la economía del enclave. Componente principal del paisaje histórico, se manifiesta en el relieve, en los cursos fluviales y en la vegetación, pero también acude a explicar lo intangible de su historia social. Segovia se presenta no solo con sus valores monumentales, sin duda excepcionales, sino como compleja combinación de lugares donde la arquitectura de sus elementos se funde en paisajes concretos dotados de una extraordinaria estabilidad espacial (De las Rivas, 2009b). Pensemos en el sistema de espacios de San Marcos, La Fuencisla y la Vera Cruz, al pie de la ciudad amurallada, o en el cercano sistema que va de la casa de la Moneda al Parral y la Alameda... se trata de conjuntos paisajísticos dotados de autonomía, pero profundamente interrelacionados. Sin una constante acción adaptativa de lo edificado y de sus usos a las condiciones del entorno natural, esto no sería posible. Esta doble cualidad de estabilidad formal y de sistema facilita la gestión de la Ciudad Patrimonio y otorga a la interpretación paisajística recursos que van más allá de lo visual, apoyándose en lo que solo la geografía histórica sabe explicar. Es el genio del lugar que dialoga en la raíz de lo que se ha distinguido como "valor universal excepcional". Pero hay que saber mirar.

Es útil la aproximación visual más sencilla, presente en los orígenes de la geografía urbana como disciplina, la visión panorámica. Segovia cuenta con excelentes miradores desde su entorno y la imagen panorámica de la ciudad demuestra hasta qué punto es una ciudad paisaje. Como en muy pocas ciudades españolas, hoy las vistas del Segovia de Anton van den Wyngaerde, del siglo xvi, podrían ser replicadas. La visión panorámica permite comprobar la relación visual sólida que existe entre la ciudad y su entorno, su adaptación al medio. Los valles del Eresma y del Clamores, ocultos si paseamos hoy entre los nuevos edificios, se mantienen sin embargo reconocibles en la distancia, reforzando la idea de la existencia de espacios de control y de permanencia que además se han instalado en el ideario colectivo, también a través de su presencia en obras artísticas y culturales (Espejo, 2012). La visión panorámica destaca en Segovia el valor protector de la naturaleza, el servicio que el enclave presta a la ciudad histórica, moderando el impacto de los desarrollos pobres.

El dibujo es, para ello, una herramienta extraordinaria, porque la representación permite activar y desactivar lo que se desea y ayuda a mirar. Ello facilita que la imagen de la ciudad en las distintas épocas de la historia se mantenga. El dibujo a la vez explica. El dibujo panorámico complementa la lectura fotográfica y puede hacer un guiño a la trayectoria iconológica de una ciudad excepcional (figura 7). Segovia en el paisaje en contraste con los paisajes de Segovia. Lo geográfico se funde en lo visual y permite descubrir, de un vistazo, la cultura de la ciudad.

El conocimiento geográfico facilita la gestión no solo porque ayuda a comprender la naturaleza de lugares y procesos, sino porque conecta con herramientas sencillas de control a través de lo visual. El espacio patrimonial, cualquier espacio ligado a la ciudad tradicional, está sometido a la tensión de la adaptación y el cambio. Si se definen los factores de permanencia de cada uno de los componentes del paisaje, un simple análisis visual permite detectar riesgos en la evolución de los espacios abiertos y de los lugares intermedios, definiendo el campo de la transformación-conservación. 

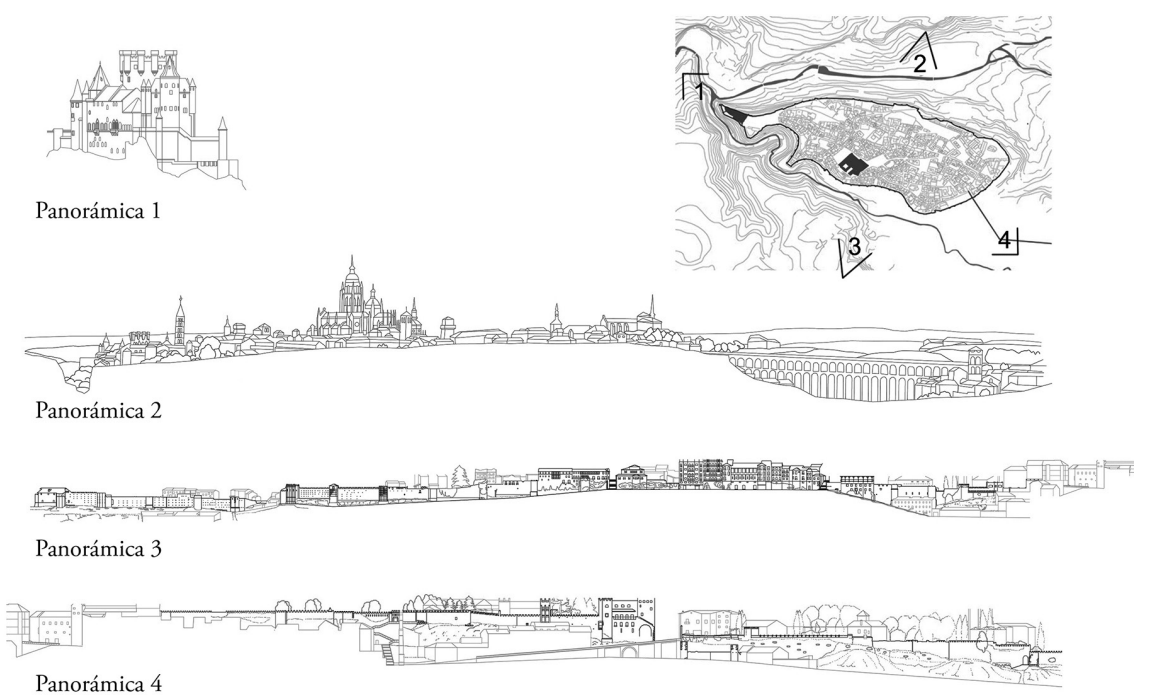

FIgURA 7 | Panorámicas y planta general de la ciudad de Segovia. Un elemento muy claro que describe este tipo de paisaje es el skyline, que relaciona directamente la forma o imagen de la ciudad con el entorno, con el que está intrínsecamente ligada, permitiendo una aproximación a su genius loci. Una aproximación que vendrá de la mano de las visuales hacia y desde la ciudad, mostrando de manera contundente el paisaje urbano y geográfico que la define.

FUENTE: ELABORACIÓN PROPIA

Sin embargo, la lectura paisajística que se apoya en la interpretación históricogeográfica de la ciudad necesita del complemento de un conocimiento preciso de la naturaleza de lo construido. Cualquier edificio valioso se inscribe en un tejido urbano, cuya estructura, textura y dinamismo han de ser comprendidos.

\section{Aproximación a la morfología de la ciudad de Segovia: forma urbana y paisaje}

El estudio de la forma urbana cambia radicalmente en Europa a partir de los años sesenta del pasado siglo con el enfoque morfológico, apoyándose tanto en el análisis que surge y se desarrolla en Italia desde la arquitectura, como con el que deriva de los trabajos pioneros de Michael P. Conzen, que se consolida en el mundo anglosajón y más próximo a la geografía urbana. Gracias al análisis tipo morfológico es posible establecer un vínculo preciso entre la forma de la ciudad y su arquitectura a lo largo del tiempo. Con un interés más centrado en las dinámicas de uso del suelo y sus lógicas latentes, la perspectiva británica de los cambios en los urban fringe belts permite completar una lectura comprensiva de la forma física de la ciudad. Se cuenta, por lo tanto, con un elenco de herramientas muy eficiente para explicar la forma construida de los espacios históricos. 
En Segovia, como hemos visto, el emplazamiento determina la forma de sus barrios históricos, una morfología urbana que, con diversos antecedentes en asentamientos celtíberos y romanos (la gran infraestructura que es el Acueducto habla de un pasado lejano tan relevante como todavía escondido), se consolida en la Edad Media. Tras un periodo de abandono, a partir del siglo XI comienza una repoblación que se impulsa en el reinado de Alfonso viI, con dimensiones territoriales que consolidan la agrupación de diversas poblaciones en la Comunidad de Villa y Tierra de Segovia. El perfil polinuclear del origen de la ciudad, con diferencias funcionales entre la ciudad alta y los barrios en las vegas del Eresma y el Clamores, da lugar a procesos de crecimiento desiguales, sometidos a las condiciones y limitaciones de cada momento histórico. El resultado es un sistema urbano complejo con morfologías diversas y difícil de administrar. Si ello ha sido posible es porque la sociedad de Segovia valora su ciudad y tiene profundamente interiorizado el deber de conservación. La aplicación de un análisis sistémico e integrador como el propuesto también puede colaborar en ello.

La complejidad y diversidad de la morfología urbana de Segovia incrementa la dimensión paisajística del sistema urbano histórico, pero también facilita el desequilibrio de las acciones de conservación en las diferentes partes que componen dicho sistema. No hay que olvidar que es el paisaje el que ata y da solidez a las estrategias de gestión de los espacios históricos de Segovia, tal y como se evidenció en el Plan Especial de San Lorenzo y San Marcos y del conjunto de espacios a lo largo del Eresma. La forma construida de la ciudad, con independencia de vaivenes funcionales, ha sido una constante tanto en la interpretación histórica, tan evidente en los trabajos de José Antonio Ruiz Hernando (1982), como en las intervenciones desplegadas en los últimos cuarenta años. No en vano la aproximación tipo morfológica sigue vigente en el PEAHIS de 2017.

La génesis, crecimiento y transformación de la trama urbana de Segovia es en cierto modo ejemplar, útil para comprender cómo el PUH puede caracterizar la excepcionalidad de un lugar y ofrecer una pauta de gestión atenta tanto al pasado como al futuro, es decir, comprendiendo la potencialidad de cada componente del patrimonio local en escenarios de futuro. La morfología urbana de Segovia destaca no por su regularidad sino por sus diferencias, que responden tanto a distintas situaciones como al largo proceso de estratificación del espacio físico, con luces y sombras en sus modificaciones, pero sin interrumpir la permanencia de sus valores históricos.

El paisaje de Segovia es una estructura de orden, con sus continuidades y discontinuidades en sus espacios intramuros y extramuros. El recinto amurallado, además de zocos y plazas mayores, de calles reales y adarves, acoge barrios cuya morfología orienta una singularidad histórica de evidente valor paisajístico en las canonjías y juderías, pero también en las casas fuertes alrededor de San Esteban o San Juan de los Caballeros, a lo largo de la Calle Real y en los interiores escondidos. Las canonjías, o claustra, responde a un modelo histórico de planificación urbana que afortunadamente hemos heredado más o menos intacto: con origen en la Galia del siglo viII, se basan en un concepto urbano de células independientes y cerradas, pero con acceso a servicios comunes, lo que las dota de autonomía. Sobre unos terrenos donados en el siglo XII por el Concejo al obispo y a la catedral de Santa María, estuvieron 
destinadas a la residencia de los canónigos y el obispo, que continuaron habitando este barrio hasta el siglo XIX. Dividido el terreno a partes iguales entre la vivienda y el jardín, se trata de una especie de ciudad-jardín, donde los espacios verdes son tan relevantes como lo construido. Las calles Judería Vieja y Judería Nueva son también espacios diferenciados, bien definidos históricamente y comunicados con el resto del recinto interior por siete puertas (en la actualidad no se conserva ninguna de ellas), con una plaza principal, plazuelas secundarias y cuatro ejes frente a múltiples callejuelas que dan acceso a las viviendas. A través de los postigos, como el Postigo de la Luna, se accedía al Cementerio Judío, al otro lado del Clamores, en la actual zona verde del Pinarillo.

En extramuros destacan no solo monasterios de la relevancia de San Antonio el Real, San Francisco o el Parral, sino barrios casi perfectos, como San Marcos, San Lorenzo o San Millán (figura 8). Dentro y alrededor de estos espacios históricos continúa la vida urbana con toda su vitalidad.

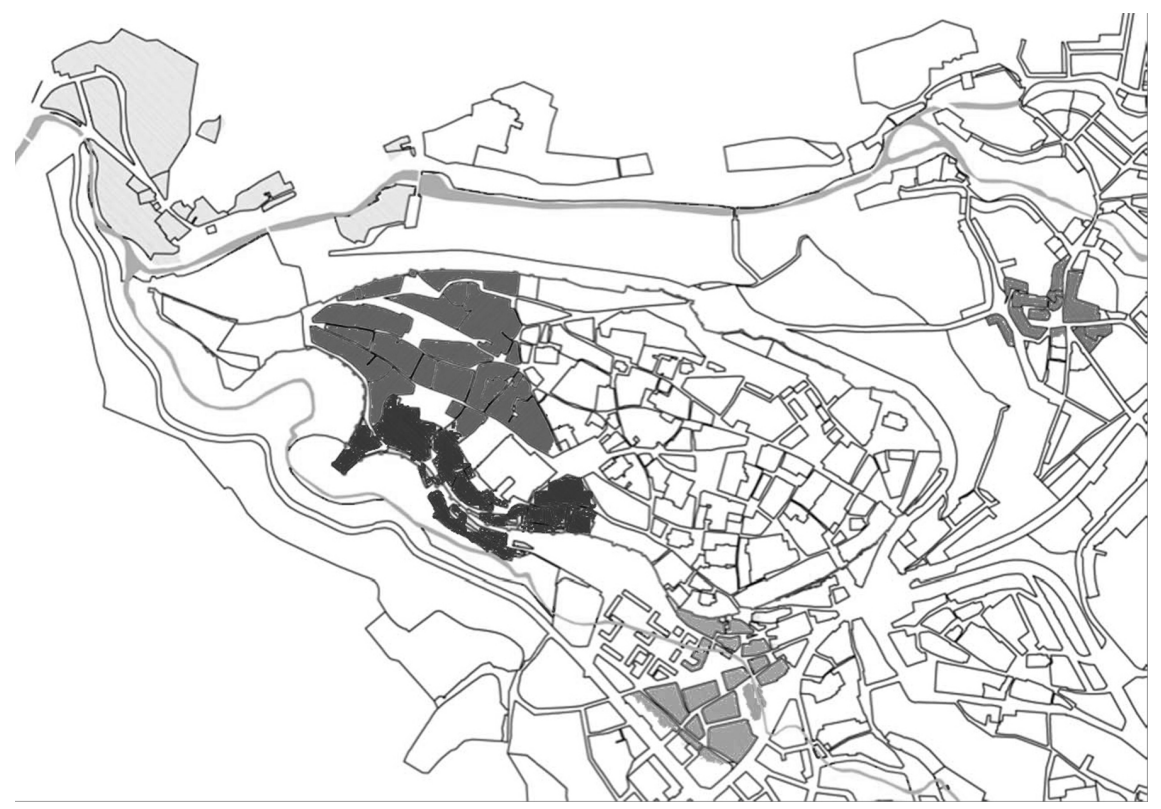

FIgURA 8 | Plano de delimitación de las zonas morfológicas e históricas más importantes, que son espacios con una identidad propia dentro de la estructura urbana de la ciudad. De más oscuro a claro: Judería, Canonjías, San Lorenzo, San Millán y San Marcos).

FUENTE: ELABORACIÓN PROPIA

La estructura del paisaje acompaña al urbanismo histórico. La puesta en valor de la morfología urbana y el complemento de un espacio abierto bien proyectado y gestionado, característicos de Segovia, protegen del crecimiento urbano inoportuno. La conservación y la regeneración urbana, con la reocupación de solares y edificios vacíos, es una derivada de esta morfología urbana consolidada y bien comprendida. 
Frente a un urbanismo a la defensiva, cargado de múltiples restricciones e incapaz de ofrecer alternativas, la calidad que ofrece a la vida urbana el impulso paisajístico y el cuidado creativo de esta morfología urbana heredada, pueden facilitar una transformación positiva y opuesta diametralmente a la pura tensión especulativa.

\section{El paisaje interior de Segovia: escena urbana y visión pintoresca}

La ciudad, su forma física, es escenario de la vida urbana, algo que es más evidente en los espacios históricos, donde se adapta la complicada vida contemporánea. La calidad del paisaje urbano histórico se mide ambientalmente, se percibe en el paseo y en la atmósfera que la ciudad ofrece. La calidad se percibe habitando la ciudad y se materializa en la visión cercana. Como si se tratara de un gran teatro, la ciudad tiene una componente escénica cargada de contenido, significante y elocuente a la vez. La ciudad histórica no se esconde. En este escenario confluyen en su día a día las necesidades y problemas urbanos, viejos y nuevos, tensores del cambio y fuente de conflictos.

En una analogía operística, no podemos controlar solo el escenario; lo necesitamos, a la vez que necesitamos la música y el libreto. Como en el teatro, las interpretaciones pueden ser diferentes y su desarrollo es lectivo, cargado de renuncias. No puede hacerse cualquier cosa. La dimensión cultural de este paisaje teatro se relaciona con cómo dicho espacio ha sido representado no solo por los imaginarios institucionales y familiares de su historia cotidiana, sino también por el arte y la literatura, contribuyendo a la creación de una escena pintoresca y protagonista, como defiende Pillet (2015), citando la obra de Azorín Doña Inés, de 1925, "donde la ciudad de Segovia se convierte en protagonista, como resultado de un proceso evolutivo que ha ido acumulando nobles construcciones rodeadas de naturaleza viva y de luminosidad" (p. 292)

Se trata de todo aquello que representa la Segovia intangible. Pero su puerta es la ciudad actual, lo que permanece en ella como escenario, paisaje urbano real acumulador de sus tiempos. Lo que vemos con nuestros ojos es la variable más elemental del paisaje, escena urbana que caracteriza la interpretación pintoresca. Pero insistimos en que este escenario refiere a la riqueza cultural de la ciudad en sentido amplio, más o menos evidente, casi siempre invisible. Podría relacionarse con elementos identificables en representaciones pictóricas, como la coronación de la reina Isabel en la iglesia de San Miguel o las descripciones de la escena urbana interior que figuran en El Buscón de Francisco de Quevedo. Se podría referir a escritos de Machado o de Lorca. Se podría verificar en los escenarios de los antiguos grabados, en el archivo fotográfico. No se trata de describir la ciudad nostálgicamente, sino de dar cuenta de lo que tiene valor.

El estudio de la imagen de la ciudad o de la escena urbana (Cullen, 1974; Lynch, 1998), de las complejas yuxtaposiciones de construcciones y significados, pone de relieve la coherencia potencial de dichos escenarios y sus limitaciones. Detectando entornos y cuencas visuales, estableciendo relaciones de forma entre elementos singulares, podemos definir factores de control y evitar que lo nuevo se levante agresivamente o en contra de lo viejo. No vale proteger solo estáticamente. Cualquier 
interpretación entraña riesgos. La vida urbana, su dinamismo, puede tanto enriquecer como deteriorar cada escenario.

Los procesos de edificación y transformación deben ser sometidos al control paisajístico (De las Rivas \& Vázquez, 2011). Su resultante no se entiende sin explicar la naturaleza de cada transformación. Cuestiones del urbanismo convencional, como la edificabilidad, las ordenanzas o los grados de protección, deben someterse a la gestión del paisaje. No sin algunos conflictos, en Segovia se ha tendido a actuar priorizando dicho control. No solo en los entornos monumentales, herramienta específicamente paisajista de la cultura urbana patrimonial arquitectónica, sino con una lógica del impacto visual y funcional más amplia.

A todo ello se puede añadir una narrativa específica que utilice la escena urbana, el paisaje interior de la ciudad (figura 9), como un recurso creador de valor, dotado de contenidos, complementando recorrido físico y relato. En Segovia existe un salón de invierno al pie de su judería, orientado al sur, entre dos postigos, de la luna y el sol. En Segovia el paseo es posible al lado del rumor del río, lejos del mundanal ruido, afín a los pasos de san Juan de la Cruz. Allí es posible la secuencia de la plaza al callejón, a la puerta o postigo y al puente, al camino del arrabal, a un lugar casi secreto (claustro, huerto o jardín). Una visión secuencial que se estructura desde la escena urbana y puede soportar recorridos de excepción. Un paisaje útil porque no pertenece solo a la descripción, sino a un proyecto de ciudad.

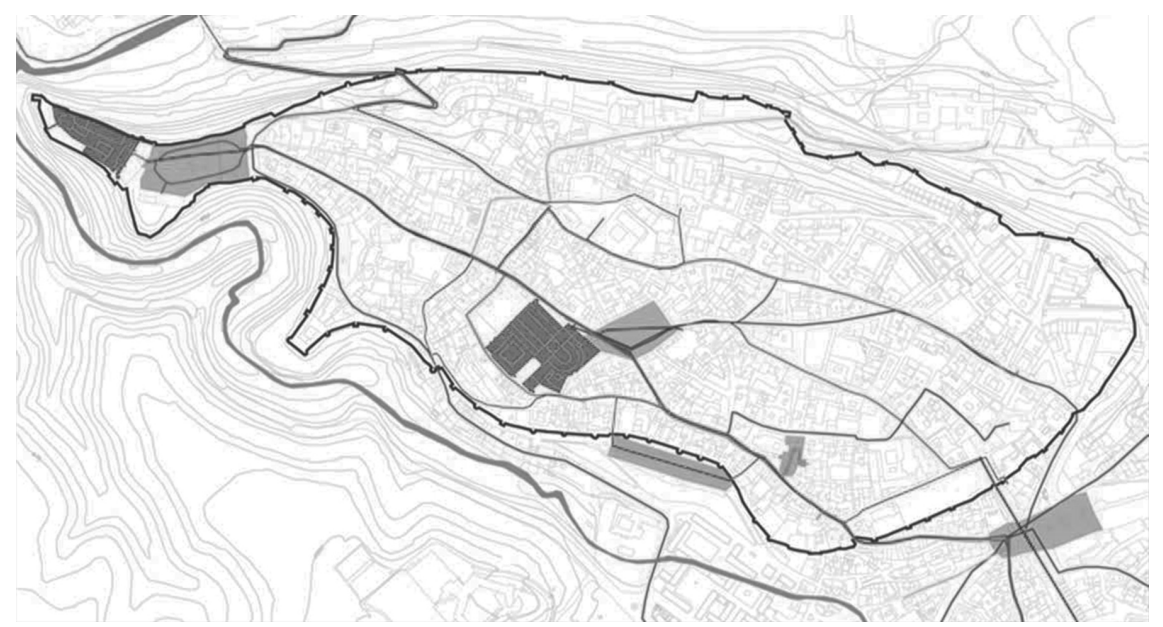

FIGURA 9 | La escena interior de la ciudad a través de sus puertas, plazas y recorridos significativos de Segovia

FUENTE: ELABORACIÓN PROPIA 


\section{Dimensiones del paisaje urbano histórico como herramienta de gestión: lo que Segovia puede enseńar}

La introducción del PUH por Unesco se produce en un contexto de fomento de un modelo sostenible de administración del patrimonio, muy centrado en la gestión del cambio y de los procesos de toma de decisiones, apoyándose en el conocimiento del lugar y en los mecanismos de participación. En el caso de las ciudades que, como Segovia, siguen siendo ciudades vivas y sometidas al dinamismo de la actividad urbana, se dice que hay que evitar formas rígidas de gestión que, en último término, perjudican la vida cotidiana de los ciudadanos y dificultan el desarrollo económico. En el extremo opuesto de lo que hoy se denomina 'turistificación' y de las dificultades de moderar la afluencia, estarían los espacios históricos sin vida. Se teme la atonía de lugares abandonados o convertidos en simples decorados históricos después de grandes esfuerzos de conservación, un riesgo que pone en cuestión estrategias inflexibles de protección. El equilibrio es difícil. Por ejemplo, en Segovia el despoblamiento progresivo de la ciudad intramuros genera gran inquietud. Ello no significa carencia de vida, pero hay un debate permanente sobre el riesgo de convertir la ciudad en un museo. Las reglas han de ser de compromiso, sometido a la capacidad de actuación, que depende de los recursos económicos locales.

Volviendo al asunto del paisaje, es inevitable que los defensores radicales de la conservación fomenten una lectura estática de la imagen urbana y amplíen los temores sobre cualquier acción transformadora. La propia lectura monumental impone la conservación de la imagen y acentúa la lógica del escenario. La solución no puede ser general, sino caso a caso, y depende de la inteligencia social de cada ciudad. Un paseo por Segovia demuestra -en nuestra opinión- que dicha inteligencia existe, más allá de debates puntuales. Las garantías de sostenibilidad y la aspiración a que el patrimonio contribuya a crear riqueza en la ciudad se benefician de la calidad del escenario, pero dependen de factores de cultura local y de coyuntura económica variables.

El estudio del paisaje y la concreción de sus componentes, definiendo el PUH en documentos de gestión, son herramientas muy útiles, no solo porque evitan la arbitrariedad, sino porque contribuyen, si están realizados con calidad y coherencia, a construir una comprensión social cohesionada de lo que se ha de conservar e impulsar. La ciudad, su paisaje, no es un escenario neutro.

No existe, sin embargo, un único camino normativo. Lo que es imprescindible hoy es que el conocimiento del paisaje urbano, que aquí se ha vinculado a una combinación de métodos de descripción y análisis de la forma urbana, y el uso de herramientas específicamente paisajísticas de interpretación y lectura de lo urbano, se incorporen con eficacia a los instrumentos de planificación y gestión de la ciudad histórica. Ya no es posible obviarlos. El Paisaje Urbano Histórico no puede incorporarse al sistema normativo solo conceptualmente: ha de afectar a los instrumentos y a los procesos de toma de decisiones. No es solo una cuestión técnica (leyes, planes, ordenanzas, programación, gestión o financiación), sino un factor que modifica el perfil del conocimiento y acentúa su interacción con los ciudadanos, que han de refrendar cada proceso. 
Como indica Salmerón (2009):

no se trata de establecer un sistema único de indicadores para las Ciudades Patrimonio Mundial, ya que los sistemas a aplicar deben ajustarse a la problemática y necesidades de cada lugar. Pero es necesario establecer criterios para su confección, diseñar un sistema que sirva de referencia y no suponga un esfuerzo difícil de llevar a la práctica y, finalmente, aplicar los indicadores a estudios de caso, rectificando, cuando proceda, la propuesta inicial. (p. 22)

\section{A modo de conclusión}

El sistema que aquí se propone parte de reconocer tres dimensiones del paisaje -la geográfica, la morfológica y la escénica-, que no deben confundirse pero que se necesitan entre sí. Se trata de métodos consolidados de análisis que facilitan un conocimiento integrado del paisaje urbano, con una vocación no solo descriptiva, sino de orden visual y de proyecto. Los criterios, variables e indicadores derivan de la concreción metodológica que en cada caso desarrolle dicho conocimiento.

Cualquier plan de gestión que quiera desarrollarse a partir del concepto de Paisaje Urbano Histórico encuentra en ello un soporte, adaptando recursos y contenidos a cada situación, a su contexto, cultura y prioridades. Porque el paisaje es no solo un objeto de estudio, sino un concepto instrumental que permite una lectura integrada, de gran potencialidad, del conjunto de recursos naturales, patrimoniales y sociales de cada lugar. Con su identidad espacial, el paisaje articula contenidos dispares dotándolos de visibilidad. Mapear resultados, representar y proyectar son acciones de conocimiento muy consolidadas que permiten incorporar a la descripción habitual una narrativa visual. Como demuestra el caso de Segovia, hay un universo complejo de referencias y conocimientos en cada lugar que, desde el paisaje, se puede reordenar y estructurar con creatividad y voluntad práctica (figura 10). Las recomendaciones de instituciones como Unesco han de servir para desplegar lo mejor del conocimiento disponible; en este caso, desde el campo del urbanismo. Lo que aquí se presenta como compendio de perspectivas y metodologías es también la defensa de una disciplina mal conocida y sometida a discursos normativos e intereses exclusivamente económicos.

En cierto modo, la definición y desarrollo del concepto de PUH destaca la autonomía del estudio de la forma urbana. Es evidente que la forma de una ciudad no se explica a sí misma, porque es el resultado histórico de una compleja acumulación de razones culturales, sociales, económicas y técnicas. Sin embargo, cabe preguntarse qué es lo que la forma urbana es capaz de explicar; en qué medida el paisaje urbano que reconocemos se puede, como objeto de estudio, interpretar. La forma urbana no se explica a sí misma; sin embargo, hay asuntos de la ciudad que solo su forma sabe explicar.

El ejemplo de Segovia y el compendio de interpretaciones que planteamos aquí para desarrollar el campo de estudio y trabajo que abre la introducción del Paisaje Urbano Histórico, tiene que ver con ello. Afirmaba un famoso estudioso del urbanismo que sabemos que la sociedad, a lo largo de la historia, da forma a la ciudad, sin 
olvidar que la forma de la ciudad también condiciona el modo de ser de la sociedad que la habita. Preservar un paisaje urbano heredado no tiene nada que ver con congelarlo; este paisaje no es una gran instalación museística, es un espacio habitado, con todo lo que ello significa de valor y de oportunidad, pero también como riesgo.

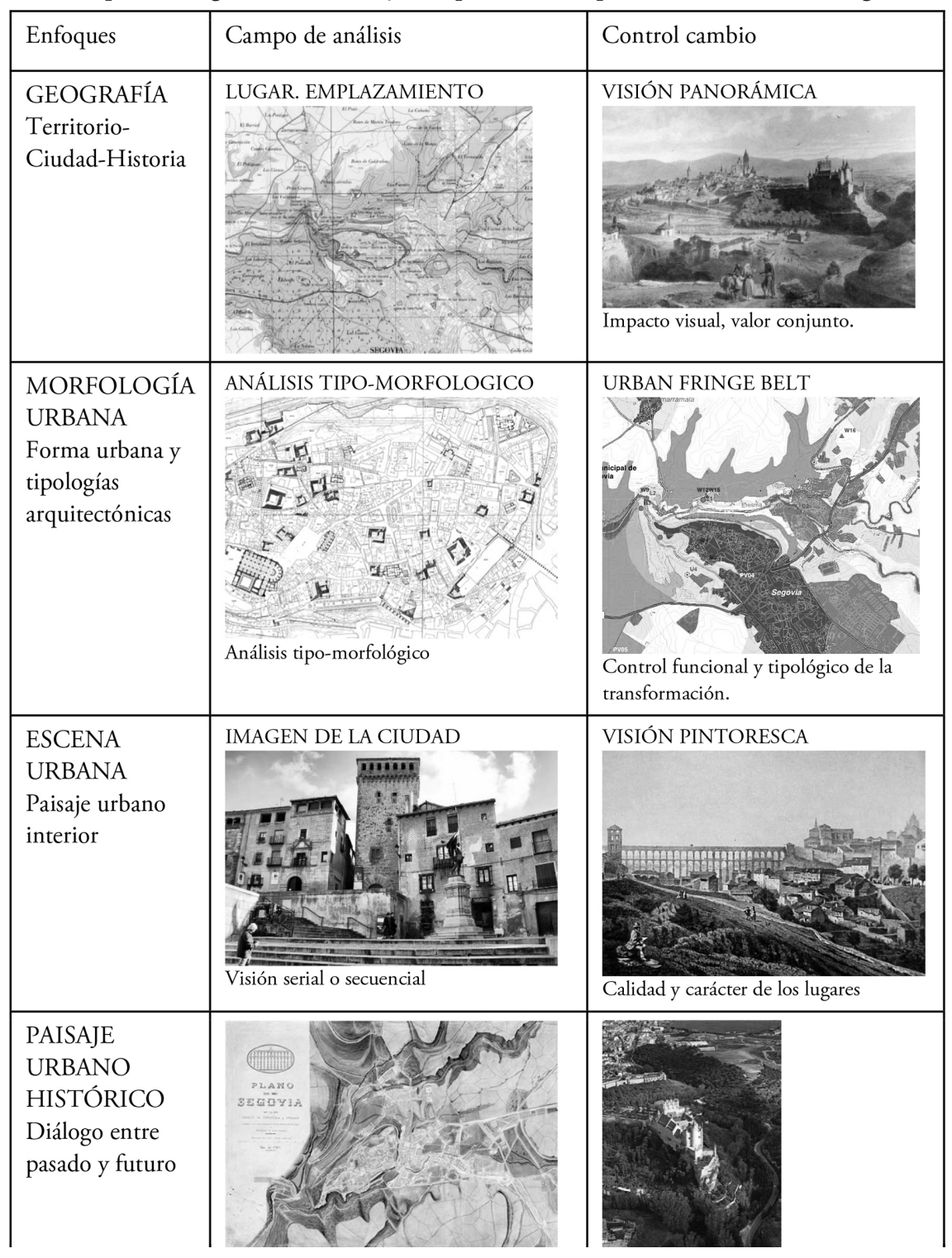

Figura io | Síntesis de las tres dimensiones que proponemos para interpretar el Paisaje Urbano Histórico. Estas dimensiones ofrecen lecturas complementarias, de conocimiento y con capacidad para orientar su gestión, ejemplificadas en el caso de Segovia.

FUENTE: ELABORACIÓN PROPIA 


\section{Referencias bibliográficas}

Aparicio Guerrero, A. E., Serrano Gil, O. \& León Irujo, D. (2018). Rehabilitación y reutilización del patrimonio urbano. Los centros históricos de nuevas capitales políticas españolas Patrimonio de la Humanidad. Cuadernos de Turismo, 42, 15-45. https://doi. org/10.6018/turismo.42.01

Bandarin, F. \& Van Oers, R. (2014). El paisaje urbano histórico: La gestión del patrimonio en un siglo urbano. Madrid: Abada Editores, col. Lecturas de Urbanismo.

Cervelllati, P. L., Scannavini, R. \& De Angelis, C. (1977). La nuova cultura delle città. Milán: Mondadori.

Chueca Goitia, F. (1998). El Alcázar de Segovia, proa de Castilla y solar de su monarquia. Segovia: Patronato del Alcázar de Segovia.

Consejo de Europa (2000, octubre 20). Convenio Europeo del Paisaje. Florencia. http://www. upv.es/contenidos/CAMUNISO/info/U0670786.pdf

Cullen, G. (1974). El paisaje urbano: tratado de estética urbanistica. Barcelona: Blume.

De las Rivas Sanz, J. L. \& Vázquez Justel, G. (2011). El paisaje urbano histórico de la "ciudad vieja" de Salamanca, claves para un plan de gestión. Revista Ciudades, 14(1), 57-80. http://uvadoc.uva.es/handle/10324/10328

De las Rivas Sanz, J. L. (2009a). Los conjuntos históricos y sus paisajes. Notas para la puesta en valor del patrimonio urbano de Castilla y León. En J. L. de las Rivas Sanz (coord.), Atlas de Conjuntos Históricos de Castilla y León (pp. 11-38). Valladolid: Junta de Castilla y León. https://bit.ly/2HHDpUX

De las Rivas Sanz, J. L. (2009b). Ciudad sobre ciudad. Interferencias entre pasado y presente en Europa. En C. Rodríguez Martín (ed.), Ciudad sobre ciudad (pp. 17-37). Valladolid: Fundación del Patrimonio Histórico de Castilla y León.

Espejo Marín, C. (2012). El paisaje de Madrid en la obra de Antonio López García. Nimbus, 29-30, 217-232. http://repositorio.ual.es/bitstream/handle/10835/2971/Dialnet-

Forum UNESCO (2009). 12th International Seminar of Forum unesco - University and Heritage. Hanoi Architectural University, Hanoi, Vietnam, 5-10 abril 2009. Presentación en http://www.catedraunescoforum.upv.es/SIFU/XII_Hanoi_2009/en/presentation. html

Lynch, K. (1998). La imagen de la ciudad. Barcelona: Gustavo Gili.

Martínez de Pisón, E. (1976). Segovia. Evolución de un paisaje urbano. Tesis doctoral. Madrid: Colegio de Ingenieros de Caminos, Canales y Puertos.

Martínez de Pisón, E. (ed.). (1977). Los paisajes naturales de Segovia, Avila, Toledo y Cáceres. Estudio Geográfico. Madrid: Instituto de Estudios de Administración Local.

Ortega Valcárcel, J. (2000). Los horizontes de la geografía. Madrid: Ariel.

Pillet Capdepón, F. (2015). La evolución de la imagen literaria del paisaje urbano de la ciudad moderna a la ciudad actual. Estudios Geográficos, 76(278), 285-307. https://doi. org/10.3989/estgeogr.201510

Rossi, A. (2015 [1976]). La arquitectura de la ciudad. Madrid: Gustavo Gili.

Ruiz Hernando, J. A. (1982). Historia del urbanismo en la ciudad de Segovia del siglo XII al XIX. Segovia: Caja de Ahorros y Monte de Piedad de Segovia; Ayuntamiento de Segovia; Diputación Provincial de Segovia. 
Salmerón Escobar, P. (2009). Paisaje urbano histórico en las ciudades históricas patrimonio mundial. Indicadores para su conservación y gestión. Reflexión sobre una experiencia. En R. Fernández-Baca Casares, P. Salmerón Escobar \& N. Sanz (eds.), El paisaje histórico urbano en las ciudades históricas patrimonio mundial: indicadores para su conservación y gestión (pp. 8-21). Sevilla: Instituto Andaluz del Patrimonio Histórico.

Troitiño Vinuesa, M. A. (ed.). (2009). Ciudades Patrimonio de la Humanidad. Patrimonio, turismo y recuperación urbana. Sevilla: Universidad Internacional de Andalucía. https:// www.unia.es/explorar-catalogo/item/ciuades

Troitiño Vinuesa, M. A. \& Troitiño Torralba, L. (2009). Turismo y patrimonio en Castilla y León: las ciudades Patrimonio de la Humanidad (Ávila, Salamanca y Segovia) como destinos turísticos de referencia. Polígonos, 19, 145-178. http://dx.doi.org/10.18002/ pol.v0i19.74

Unesco (Organización de las Naciones Unidas para la Educación, la Ciencia y la Cultura) (2006). State of Conservation of World Heritage Properties in Europe. Section II. SPAIN, Old Town of Segovia and its Aqueduct. https://whc.unesco.org/document/163255

Unesco (Organización de las Naciones Unidas para la Educación, la Ciencia y la Cultura) (2011, noviembre 10). Recomendación sobre el paisaje urbano histórico, con inclusión de un glosario de definiciones. Unesco.org / Instrumentos normativos. https://bit. ly/2LwkEZy

Unesco (Organización de las Naciones Unidas para la Educación, la Ciencia y la Cultura) (2014, abril 16). Informe sobre propuesta de procedimiento, Modificación Menor del Bien inscrito en la Lista del Patrimonio Mundial de "la Ciudad Antigua de Segovia y su Acueducto" para la creación de una zona de amortiguamiento alrededor del Bien. https:// whc.unesco.org/document/158609 
| OTROS ARTÍ́CULOS 
